\title{
Facilities Planning for a Creative Company
}

\author{
Gabriel Bouhid Barradas \\ Federal University of Rio de Janeiro (UFRJ), Rio de Janeiro, Brazil \\ Regina Reis da Costa Alves \\ Petrobrás-Brazillian Oil Company S.A., Salvador, Brazil \\ Vinícius Carvalho Cardoso \\ Federal University of Rio de Janeiro (UFRJ), Rio de Janeiro, Brazil
}

\begin{abstract}
Facilities planning tools have been used by project managers for planning industry spaces for decades now, but applications in creative organizations are still sparse. This happens mainly because of a gap that exists between engineering and psychology fields, with the first developing planning tools for production but with little concern for creativity and the other developing spaces for creativity, but with a lack of tools. Both try to solve the same issue: fostering productivity in the workplace, but they need to be linked first, in order to accomplish it. How to close this gap? Can a project manager plan the facilities for a creative organizational in the best way possible? In this paper, a new approach is used for studying the design of physical environments that foster organizational creativity, combining the results of psychological studies on the impact of physical environment on creativity with the facilities planning body of knowledge applied by industrial engineers. In order to test the results, a single case study is developed in a small IT consulting firm. By using the systematic layout planning (SLP) step by step process, it is shown that by acting on the work environment of the company, the developers creative processes can be boosted and facilitated. It is also shown that both industrial engineering and creativity research have much to contribute to each other and future research topics in the field are presented.
\end{abstract}

Keywords: creativity, creativity management, facilities planning, physical spaces for creativity, creative spaces, organizational creativity, systematic layout planning (SLP)

\section{Introduction}

This article presents a facilities planning project for fostering creative performance in the workplace of an IT developing company. In order to do this, analyzing tools from the decades old facilities planning body of knowledge from the industrial engineering literature are used as well as present alternatives taking into account recent studies on creativity psychology. Studies of creativity are relatively new — commencing at 1950's — and just recently have drawn attention to the lack of studies on the impacts of the physical workplace environment on the creative work results (Kristensen, 2004; Haner, 2005). Engineering can bring inputs to this discussion

Gabriel Bouhid Barradas, industrial engineer, Federal University of Rio de Janeiro (UFRJ), Rio de Janeiro, Brazil.

Regina Reis da Costa Alves, M.Sc. in computer engineering, Petrobrás-Brazillian Oil Company S.A., Salvador, Brazil.

Vinícius Carvalho Cardoso, D.Sc. in industrial engineering, Federal University of Rio de Janeiro (UFRJ), Rio de Janeiro, Brazil.

Correspondence concerning this article should be addressed to Gabriel Bouhid Barradas, Federal University of Rio de Janeiro, Escola Politécnica, Av. Athos da Silveira Ramos, 149, CT, Building F, Room F-101, Cidade Universitária, Rio de Janeiro, RJ, Brazil. ZIP: 20271-110. 
and in order to do that, a case study on a company, that has a creative result as its main product - consulting, is presented as a way to show that both the engineering and the psychology fields can exchange knowledge to help each other in this matter.

Researches show many ways to create sensations that can influence workplace creativity. Some suggest the balance of stimuli as a source for aiding both the divergent and convergent nature of creativity, as well as group activities being balanced with individual ones (Haner, 2005). The divergent nature of the creative process is the step when the persons search and "digest" information, leading to a generation of ideas. The convergent nature is related to analytical activities, like sorting, filtering, and developing the ideas that may eventually lead to an innovation. The presence of plants, flowers (Shibata \& Suzuki, 2002; 2004) and windows with views (Stone \& Irvine, 1994; Steidle \& Werth, 2013), the use of raw materials (Doorley \& Witthoft, 2012), dim illumination (Steidle \& Werth, 2013), high ceilings (Meyers-Levy \& Zhu, 2007), and asymmetric spaces (Kristensen, 2004) have all been associated with more freedom and are deemed best for the divergent steps of creative tasks. More so, many experiments on physical environments for creativity highlight the great importance of meetings among people, mainly face-to-face interaction — but also virtual encounters - as the most important activity in order to achieve creative insights (Tompkins, White, Bozer, \& Tanchoco, 2010; Oksanen \& Ståhle, 2013). The sharing of tacit knowledge between workers is the main core for developing a facility that focus on creative processes (Hong, Hwang, \& Lin, 2003). Also of relevance is the availability of information sources, presentation devices, and information systems that might support the knowledge sharing and the knowledge management (Kristensen, 2004; Magadley \& Birdi, 2009). In order to do this, the facility should have both working and meeting spaces for informal and formal sharing of information and tacit knowledge.

For the convergent steps of the creative process, the physical environment will have different needs. While for the divergent steps, it supports openness, freedom, and fuzziness, for the convergent, it must focus on concentration, discipline, and analytical thinking. Silent, orderly and private spaces may prove most useful for this kind of activity (Block \& Stokes, 1989). Thinking zones with little disturbance from the outside and other workers are as necessary as the open environments and the meeting spaces in order to accomplish a full creative process. The problem now being is how a facility can be at the same time open and closed, a place for group encounters and sharing as well as a place for lonely analysis and individual thinking, aiding both divergent and convergent steps.

In order to tackle this problem, some authors have proposed ways to organize facilities that join the technological, emotional, social, and other innovation-enabling factors in the workplace. Multi-space environments consist of spaces or offices with multiples rooms that have adjustable furniture, adjustable spaces, and atmospheres consistent with the kind of work being performed and with information presentation and retention abilities. These multi-space environments are proving to be a solution that can foster the face-to-face communication, the divergent thinking, and the convergent thinking at the same facility (Augustin \& Brand, 2001; Haner, 2005; Boutellier, Ullman, Schreiber, \& Naef, 2008; Peschl \& Fundneider, 2014). The working space should be planned in a conscious way, instead of an ad-hoc way, and one should consider issues like the organization innovation strategy and hierarchy status of employees (Moultrie et al., 2007).

The research presented about the physical context for creativity may bring great contributions to organizational creativity but most still lacks some features that are needed for engineering projects, like a deep understanding of the operations process and a traceable planning process for the facility project. Facilities planning is a subject that deals with optimization problems with the objective of improving layout efficiency, 
taking into account all the physical aspects of a facility and the interaction between the facility and the parts that constitute the work processes, like material handling, machinery, and people (Shayan \& Chittilappilly, 2004; Heragu, 2006; De Carlo, Arleo, Borgia, \& Tucci, 2013). Tompkins et al. (2010) proposed a holistic approach, pointing out that five characteristics facilities must be contained: flexibility, modularity, upgradability, adaptability, and selective operability. The industrial role of the facility layout problem is wide spread and can be found in numerous references in the literature (e.g., Yang, Su, \& Hsu, 2000; Chien, 2004; Van Donk \& Gaalman, 2004; Wiyaratn \& Watanapa, 2010; Ojaghi, Khademi, Yusof, Renani, \& Hassan, 2015). Comparatively, there are few studies that deal with the services organizations (Block \& Stokes, 1989; Brooks, 1998; Augustin \& Brand, 2001; Brennan, Chugh, \& Kline, 2002; Boutellier et al., 2008; Danielsson \& Bodin, 2008) and none of those has tried to apply layout solution methods to creative facilities yet. In order to accomplish this, the Systematic Layout Planning (SLP) (Muther, 1973) method is used as a mean to close these gaps left by the creative spaces researches.

The SLP is a method for the design or redesign of a facilities layout and is the most widely used among organizations and handbooks (e.g., Yang et al., 2000; Van Donk \& Gaalman, 2004; Wiyaratn \& Watanapa, 2010; De Carlo et al., 2013). Since its development in 1973, it continues to evolve through its application by many engineers and studies that assess its algorithms and procedures. The method is based on the understanding of five key aspects of production — material, volume, process, support service, and time - in order to achieve an outstanding planning. The method also has the additional benefit of its step-by-step tools, which make each step of the project explicit and traceable, facilitating explanations to workers and managers.

In this paper, the union of the SLP method with the organizational creativity physical environment studies is addressed. One of its objectives is to understand how an engineer could plan the facilities for a creative organizational in the best way possible taking into account all its processes and its structure; and for this, the union of the two bodies of knowledge presented is tested. The focus is on a contemporary event that does not require control of behavioral events in order to answer the research inquiry; as a way to get to the best results, the research strategy is a case study. The fact that this study is just trying to take a first step and show that the union between organizational creativity and the SLP method can be accomplished with positive results points towards a single case study (Yin, 2014). This paper shows that this union is possible and it may work in a real creative organization environment. This first step could be a base for other engineering projects to be developed and researchers may test this method on other cases as a way to foster the evolution of the facilities planning subject for creative organizations as it has happened before for the industrial organizations.

\section{Case Study}

The enterprise which was chosen for this work belongs to the energy sector and has two main activities: consulting and software development for decision support. It has a flexible hierarchical structure: The employees are actively engaged in the projects' choice and help in the tasks and priorities definition. A CEO, eight directors, and four teams compose it: software development, consulting studies, and two support teams - the IT team and the administrative team.

For the consulting activities, the main areas are investment analysis, bioelectricity, risk management, asset evaluation, expansion planning, market design, strategic consulting, and environmental studies.

Although a client orders the studies, they contribute to the enterprise's learning process and are an information source to the software development team. Similarly, the studies explore the software developed 
inside the enterprise. The projects inside these areas vary greatly, which explains the complexity involved in them. Their development is made using already acquired knowledge and experience, new researches, and involves creative work.

Considering the software developments, it is possible to highlight four main activities related to it: doubts assistance, error finding and solution, launching of new versions (improvement in the software), and software selling.

The doubts assistance consists only in helping the customers with the software functionalities. Sometimes, the customer may find errors during an execution and the employees must find the cause and propose a solution to it. This solution may or may not result in the launching of a new software version. The new versions include improvements and new functionalities developed by the team.

There is also a job of contacting the customers to sell the developed software. Sometimes there are specificities in a client's version and the enterprise also offers to hold courses about the software which was bought.

In the next sections, the activities conducted in the enterprise are analyzed by adapting concepts of the SLP method. This will be the starting point to evaluate the enterprise's physical environment and propose alternative layouts, which could be more suitable to the enterprises' necessities.

\section{Product Quantity (PQ) Analysis}

In the SLP method, the PQ analysis is made to define which product is more relevant to consider in the layout project, so that the transport effort is minimized. In the considered case, the objective is not to minimize transport efforts, but to improve the physical environment, so that it becomes more suitable to the enterprise's activities, which are predominantly cognitive and do not involve tangible products.

As the products are not tangible, it is not possible to relate directly the quantity produced with the physical environment. Nevertheless, if certain activities are more frequently done in the enterprise, the layout planning should consider that during a significant part of time, the employees will be dedicated to them.

The analogy proposed to develop a PQ analysis is to consider the percentage of time spent in each of the enterprise's products. The different activities related to the enterprise's software and the consulting projects divided by the main areas that were previously presented are considered as "products".

For the consulting activities, Figure 1 shows the percentage of projects corresponding to each area.

Considering the software development, it was informed that the percentage of time dedicated to each software can be well approximated by the percentage of users corresponding to it. This is intuitive: More users lead to higher demands for errors solution, questions answering, and development of new features. Figure 2 shows the percentage relative to the total number of users for each software.

The percentage of time spent in doubts assistance, troubleshooting, launching of new versions (improvement in the software), and software selling, for this work, was determined based on the employees' impression, as sometimes they can work simultaneously in two or more of these activities. According to them, about $60 \%$ of the time is spent in customer service (20\% questions and $40 \%$ troubleshooting) and $40 \%$ in the development of new features.

In order to unify the information about the proportion of time spent in products that is divided between the consulting area and the development area, to unify the information, a number of daily hours spent in each area are estimated. Simply put, considering that employees work eight hours per day and knowing each area's number of employees, one can find the total daily hours spent in each product, as shown at the PQ analysis graph (Figure 3). 


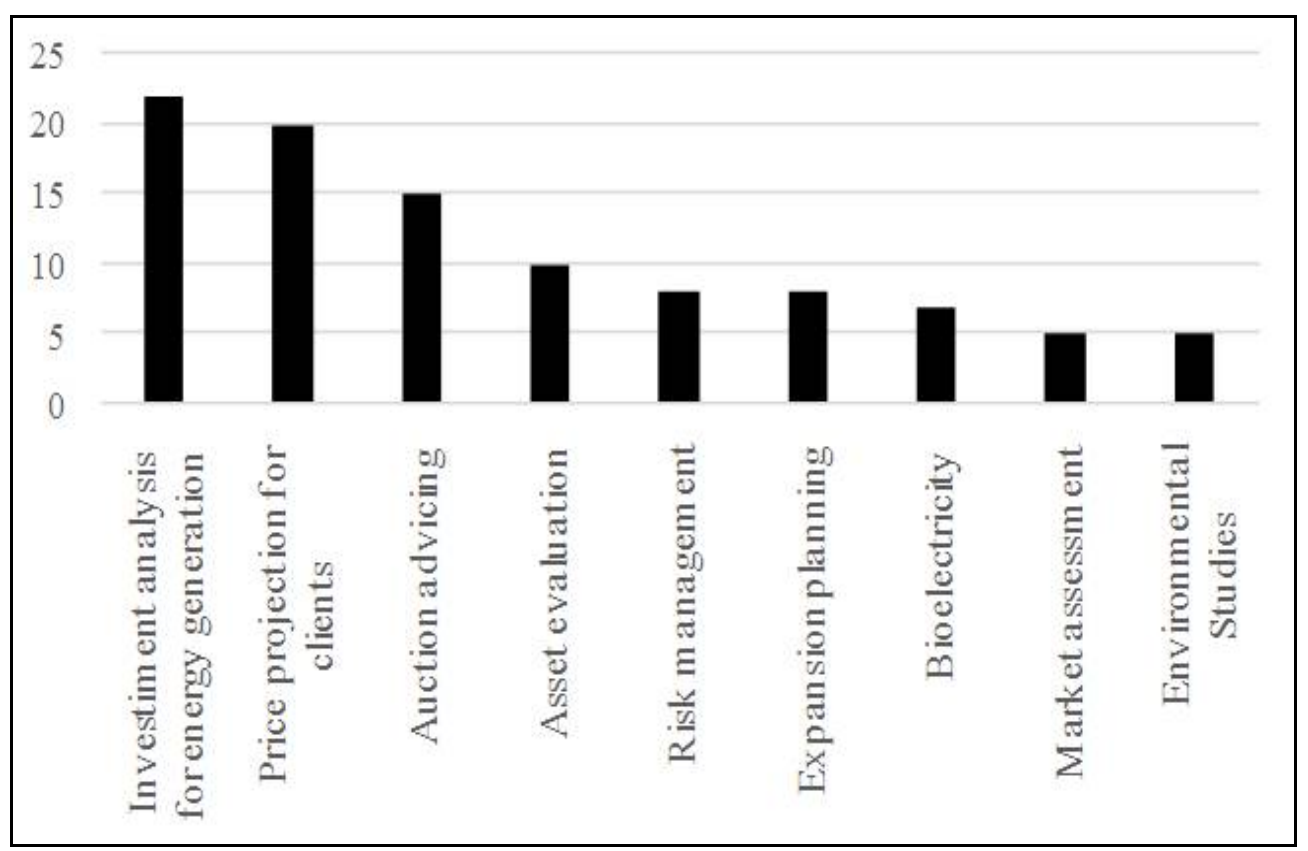

Figure 1. Percentage of projects corresponding to each area.

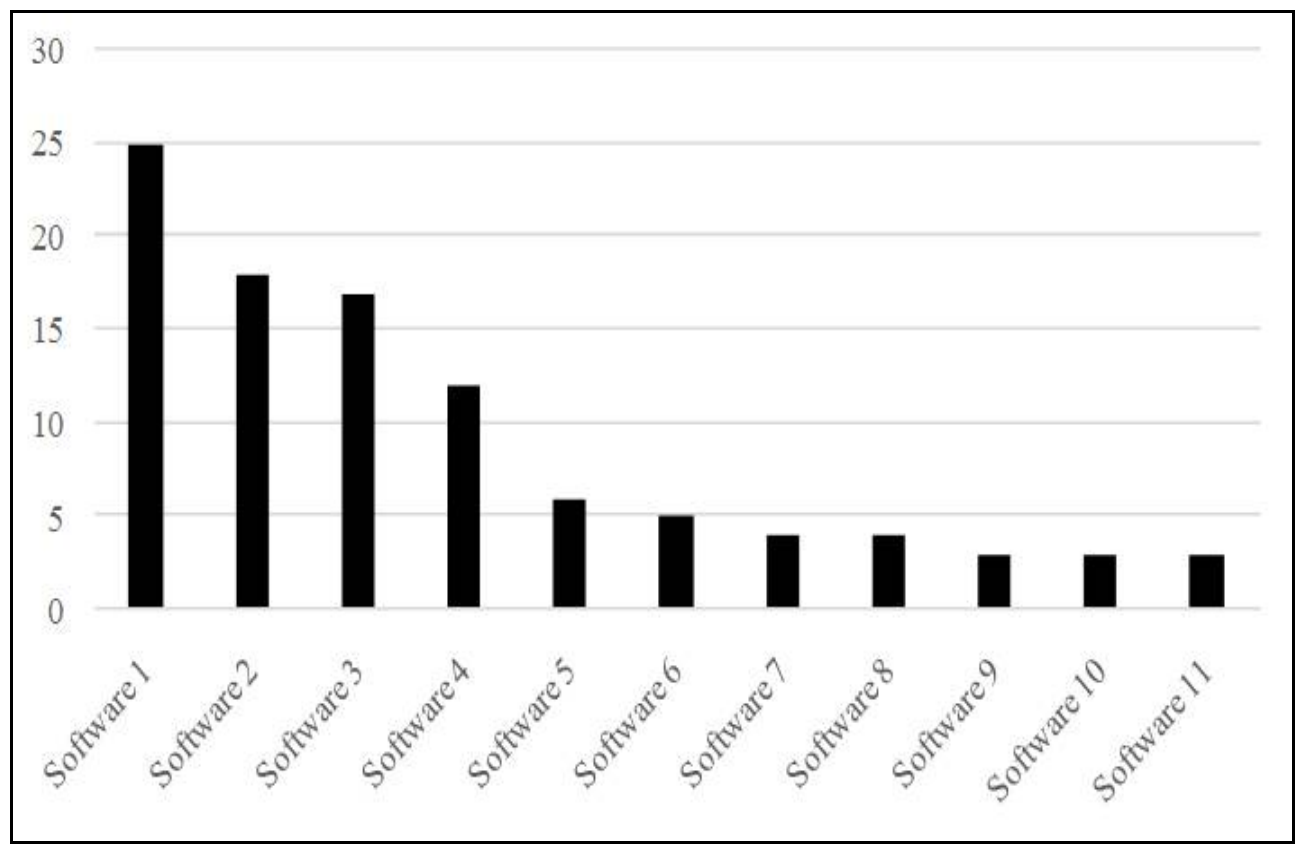

Figure 2. Percentage relative to the total number of users for each software.

As shown in the Figures, the consulting activities corresponding to investment analysis and prices projection for consumers, added to the support activity related to software 1 , represent more than $10 \%$ of the total dedicated time. In analogy with the fast movers in the SLP method, this can justify specialized resources (material and people) and layout for these products. For creative and cognitive activities, this can be expressed by: the creation of rooms for the development of these activities; specialized communication resources, information and media; and people fully dedicated to these activities. 


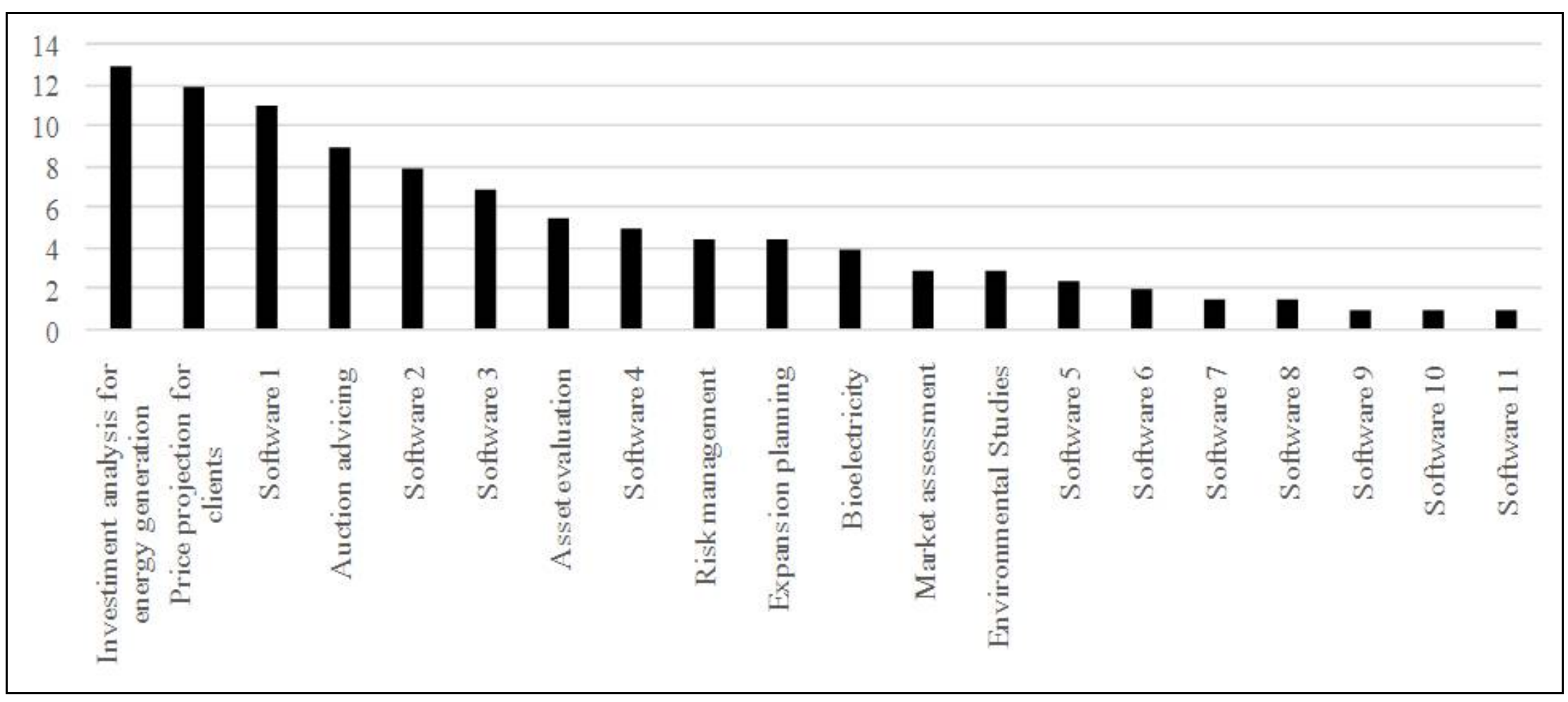

Figure 3. PQ analysis graph. 
The fact that the considered environment is small prevents the existence of many specialized rooms. There is a strong interrelationship among the areas, due to the use of decision support tools for consulting and to the information input given by the consulting team to the software development team. There are also interconnections between different consulting projects and different software. Consequently, it is quite advantageous that people are in a common environment. This means that this analysis alone will not determine the environment configuration.

\section{Production Processes Analysis}

Following the SLP method, after defining the priority products, the material flows within the plant must be measured, either by flowchart, by multiple processes chart, or from-to chart. Ultimately, this information will be used in order to understand the proximity necessities between the process locations and handling systems.

In this case, as the products are intangible, instead of analyzing a product by its material flow, it is important to describe the stages in a product creation process and understand its exigencies, considering the tacit and explicit knowledge's creation and transmission.

Different stages in the development of the same product may demand different cognitive tasks. For instance, the creative work, according to Haner (2005), involves activities of both divergent and convergent nature, as well as activities in group and individual ones. The activities also involve different difficulty levels in the tacit and explicit knowledge creation.

For this analysis, products are grouped into three categories: troubleshooting, new features development, and consulting activities. This was done because the troubleshooting processes and the new features development are quite similar for all the software, and as the consulting processes are specific to each project, they were grouped in a general process.

Troubleshooting and doubts. When the error source is not evident, the following steps are to search for the error, send error to the development team, and make tests after corrections. The degree of complexity of these steps is variable and usually depends on the employees' tacit knowledge. For the majority of errors, only one employee is involved in the error solution. According to Block and Stokes (1989), individuals feel more satisfied in private settings, as opposed to open offices, when executing complex tasks, which may be related to a convergent stage of the creative process for the troubleshooting activity.

In cases of high degree of complexity, the activities of searching and making tests may involve more than one person, typically two or three, and a tacit knowledge socialization process occurs. In this activity, the employees' experience sharing is more relevant than theoretical studies in the learning process. If the solution is still not found, formal meetings involving members of the software team, or even all members, may take place. However, even in this case, the individual work time is much longer. From the perspective of the creative process stages (Wallas, 1926), the preparation process requires more individual work than the exchange of knowledge.

The users' questions answering activity typically does not require a creative process, but a process of knowledge externalization and socialization. Regarding the physical context, this process requires appropriate communication tools, but based on the present study, it is not evident that it needs a specific space configuration, besides a minimum silence required to communicate with the client.

Development of new features. In the development of new features, the exchange of knowledge is much more intense and usually involves employees from different teams, both consulting and software development 
personnel, and even people outside the enterprise: customers who pay for this development and people who have specific knowledge. In this enterprise, it is common, for example, to invite people to give talks about a specific topic for employees.

From the standpoint of the creative process stages (Wallas, 1926), the preparation stage is usually long, can last for months, and requires intensive exchange of tacit and explicit knowledge. Some authors stated that the clusters are more suitable for these activities, with shared spaces where people can easily contact each other, facilitate this process. Therefore, it is very important to keep the current configuration of open office for this activity.

After the discussions, there is a stage for the new features implementation and tests, which can be long and is typically individual.

Consulting projects. For the consulting projects, the preparation stage necessarily involves customers who hired the project and meetings can take place within or outside the enterprise. In this step, the project will be defined in general steps, needing further detailing. It is possible to consider that the subsequent stages correspond to the verification stage in the creative process stages model. In this stage, the ideas which were previously discussed are developed.

At this stage, the existence of an open office is also important; in fact, during the projects development, the exchange of information between the involved members is quite frequent. In general, the projects involve three or four people. Furthermore, for the selection of the appropriate software to be used by the project, it is important to exchange information with the software development team.

\section{Physical Environment}

Today the CEO has an individual office; the directors work in a shared office, each one with two people; the administrative team work in a small open office, with five people; the consulting, software development and IT team work in the same open office; and at last, there are three meeting rooms, two bathrooms, and a common social area for coffee breaks. Once a week, there is a big coffee break in this area.

All the directors' and the CEO's office, the bigger meeting room and the common social area have big windows. The bigger open office has four big tables, each one fitting eight people (four each side), with one computer per person. All the meeting rooms have a central table and a whiteboard. The bigger meeting room has also a projector. All the walls are white, there are no plants, the lightening and temperature are classified as very good by the employees, and the noise level in the open office is classified as moderate/high by the employees.

\section{Relationship Diagram and Layout Alternatives}

In the SLP method, preferred interconnections are made considering pre-determined physical areas (blocks), through which the factory's products flow and in which support activities are found. The importance of interconnection can be determined by qualitative criteria and quantitative data collected in the previous steps are organized into classes of importance AEIOUX.

In this case, there is no tangible material flow, but there are also proximity necessities among process locations. The previous discussion shows that all the activities held by the enterprise have stages of predominantly individual work as well as stages of predominantly group work. Organizations with multi-space - with many spaces to individual or group activities - are ideal, with places to divergent and 
convergent, individual, or group thoughts (Haner, 2005; Boutellier et al., 2008), in other words, supporting all the stages of the organizational creative process. The existence of multi-spaces breaks the monotony and is positive for creative work (Boutellier et al., 2008).

Stokols, Clitheroe, and Zmuidzinas (2002) suggested that, for individual and complex tasks, an environment with high level of distractions, like a noisy place, affects creativity and job satisfaction in a negative way. Thus, it is important to create a space proper to individual work, which is not present in the enterprise layout. One way is to add a room without fixed places for each employee and not necessarily comporting all the enterprise's employees at the same time, but still keeping an open office for the consulting, software development, and IT teams.

Figure 4 and Figure 5 consist in the developed relationship diagram and relationship chart. On the diagram, the poor relation type $\mathrm{O}$ (somewhat important) is excluded because, as the company is small, any distance could already be considered a distance of little importance. For the blocks positioning, the studies about the impact of the proximity to windows in job satisfaction and in the encouragement of creative work (Stokols et al., 2002; Steidle \& Werth, 2013) are also considered. Bold double lines are absolutely necessary relationships, simple lines are very important relationships, and dashed lines are important relationships.

\section{Spaces Determination}

To determine the spaces, the measures of the current layout are used as basis and some small changes are made. This need comes mainly from the fact that, considering what has been presented above, there is a necessity of creating a new space in the enterprise, which would be suitable for individual work, to serve eight people or approximately $25 \%$ of employees.

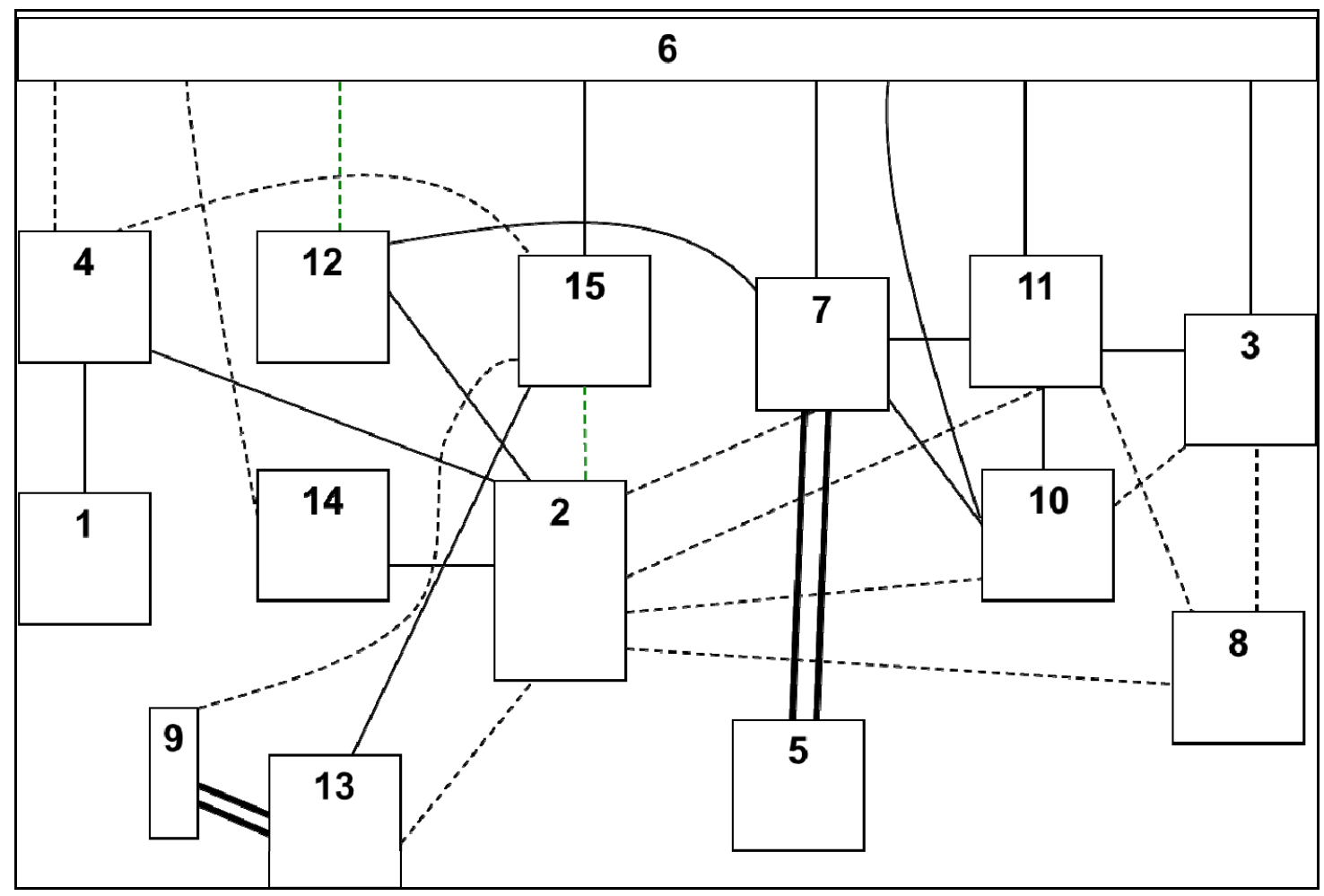

Figure 4. Relationship diagram. 


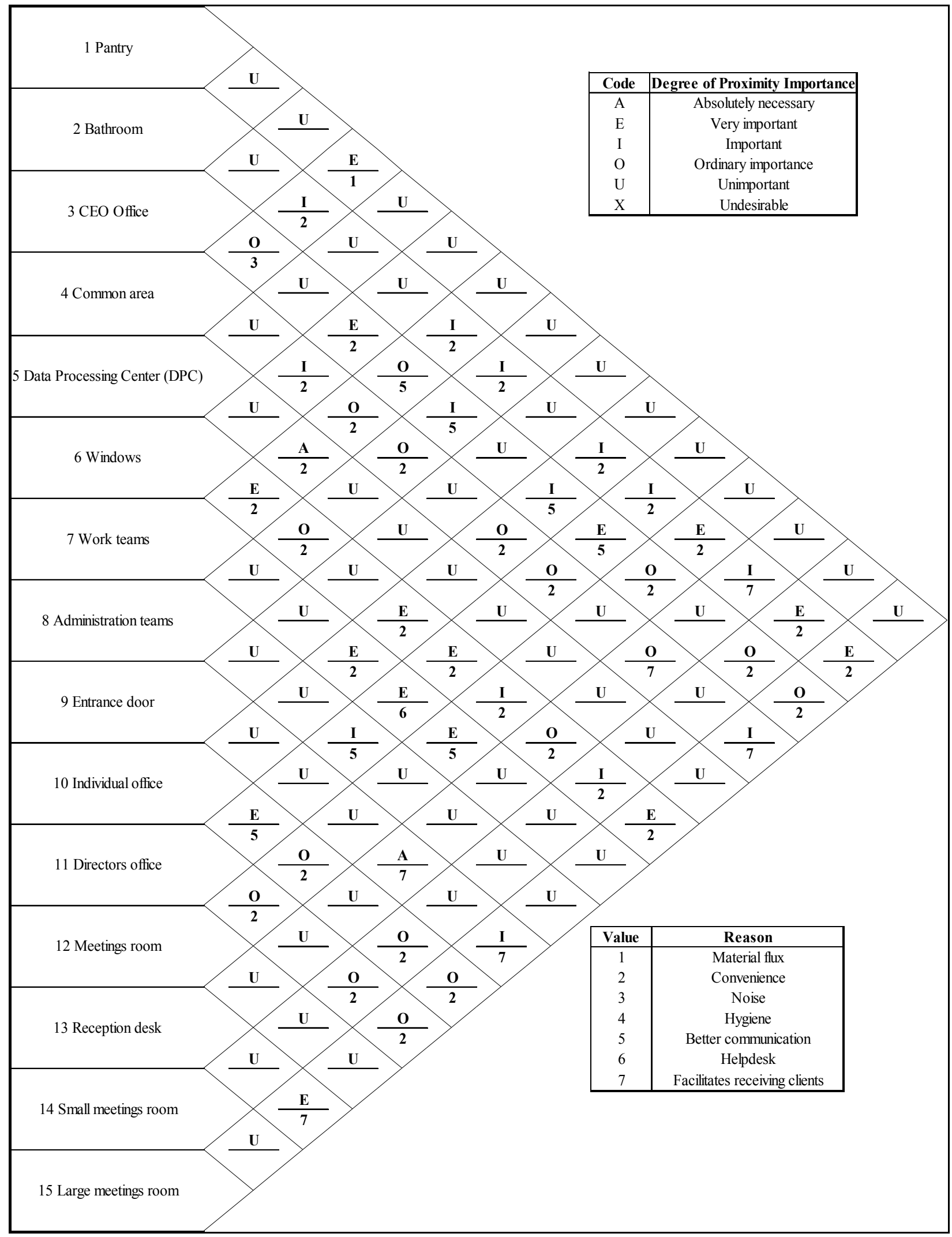

Figure 5. Relationship chart. 
Interviews with the management team have shown that it is very rare that the three meeting rooms are occupied simultaneously. Meetings with customers, for instance, are not very frequent. Therefore, a decision to remove one of the meeting rooms is made, since, according to the administrative staff, two would be enough for the enterprise's meetings frequency.

The resizing refers to meeting rooms and directors' offices. Currently, each director's office is occupied by two directors. In the layout alternatives that will be further presented, there are three directors' offices and one office for the CEO. This change was considered as possible after analyzing the workspace required for each director (Iida, 2005):

- Table: $1.0 \times 0.7=0.7 \mathrm{~m}^{2}$;

- Chair: $0.5 \times 0.5=0.25 \mathrm{~m}^{2}$;

- Workspace: $1.6 \mathrm{~m}^{2}$;

- Circulation space: $1.4 \mathrm{~m}^{2}$;

- Bookcase/cabinet: $1 \mathrm{~m}^{2}$. The data, taken from the present plant and rounded to whole numbers, are below:

- Managers' offices: $13 \mathrm{~m}^{2}$;

- Living room: $90 \mathrm{~m}^{2}$;

- Large meeting room: $20 \mathrm{~m}^{2}$;

- Average meeting room: $12 \mathrm{~m}^{2}$;

- Small meeting room: $8 \mathrm{~m}^{2}$;

- Coffee space: $10 \mathrm{~m}^{2}$;

- Men's bathroom: $6 \mathrm{~m}^{2}$;

- Women's bathroom: $6 \mathrm{~m}^{2}$;

- Reception: $16 \mathrm{~m}^{2}$;

- Secretary: $21 \mathrm{~m}^{2}$;

- Cup: $4 \mathrm{~m}^{2}$;

- CPD: $8 \mathrm{~m}^{2}$

\section{Block Layout.}

Alternative 1. In this alternative (Figure 6), two of the directors' offices are removed and the other four (three directors' office and the CEO's office) are expanded, which could fit three people per room instead of just two. This was done so that the development, consulting, and IT teams could have access to the window in the area in gray. For this, the room must have a glass wall, which can be isolated from the common social area vision if necessary by a shutter or similar device.

The entrance and reception locations were modified, so that the reduction of the common social area is compensated by the increase of its length. This area was kept in the alternative based, for instance, in the study developed by Hong et al. (2003), which states that an office should have both working and meeting spaces and should support informal knowledge-sharing, as well as the suggestion of taking into special consideration amenity spaces (e.g., relaxation rooms, gardens, and cafes) made by Tompkins et al. (2010).

The gray area was occupied with a multifunctional room, which replaced one of the meeting rooms, and is projected not only to be used in formal meetings, but also to have a central position in relation to the directors' and staff's offices. This choice was based on the suggestion made by Kristensen (2004), stating that radial 
configurations in the physical space facilitate spontaneous meetings among people. According to the same author, the availability of tools for the ideas' externalization is important in the creative process and this room's main objective is to provide them to employees (media resources, whiteboards, etc.).

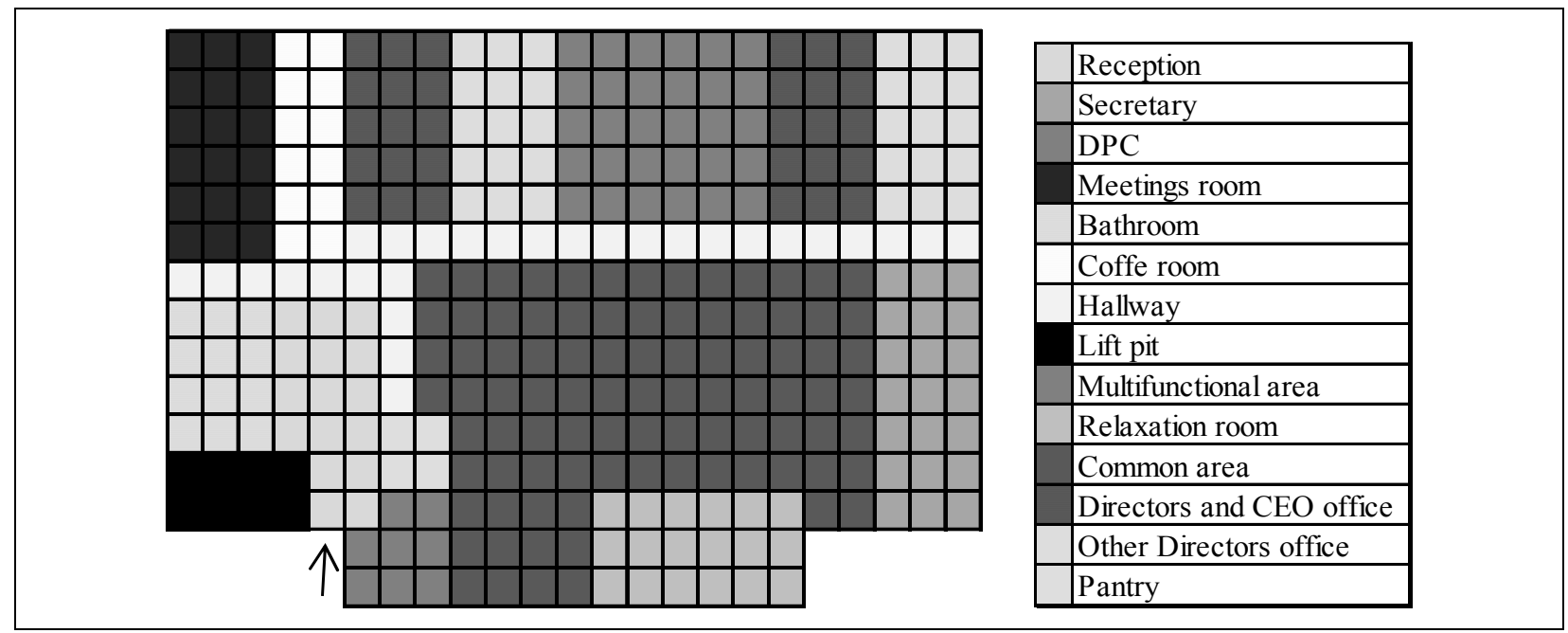

Figure 6. Layout alternative 1.

Alternative 2. In this alternative (Figure 7), one of the meeting rooms was removed in order to enlarge the common social area and the multi-purpose room in $17 \mathrm{~m}^{2}$ and $10 \mathrm{~m}^{2}$, respectively. The withdrawal of this room is compensated by the possibility of splitting the multi-purpose room into two smaller rooms, thus maintaining the possibility of two simultaneous meetings. The common social area is also smaller, but in this alternative, it has a central position in the company. The idea is that the multi-purpose room, now expanded, can be also used as a common social area for employees and customers.

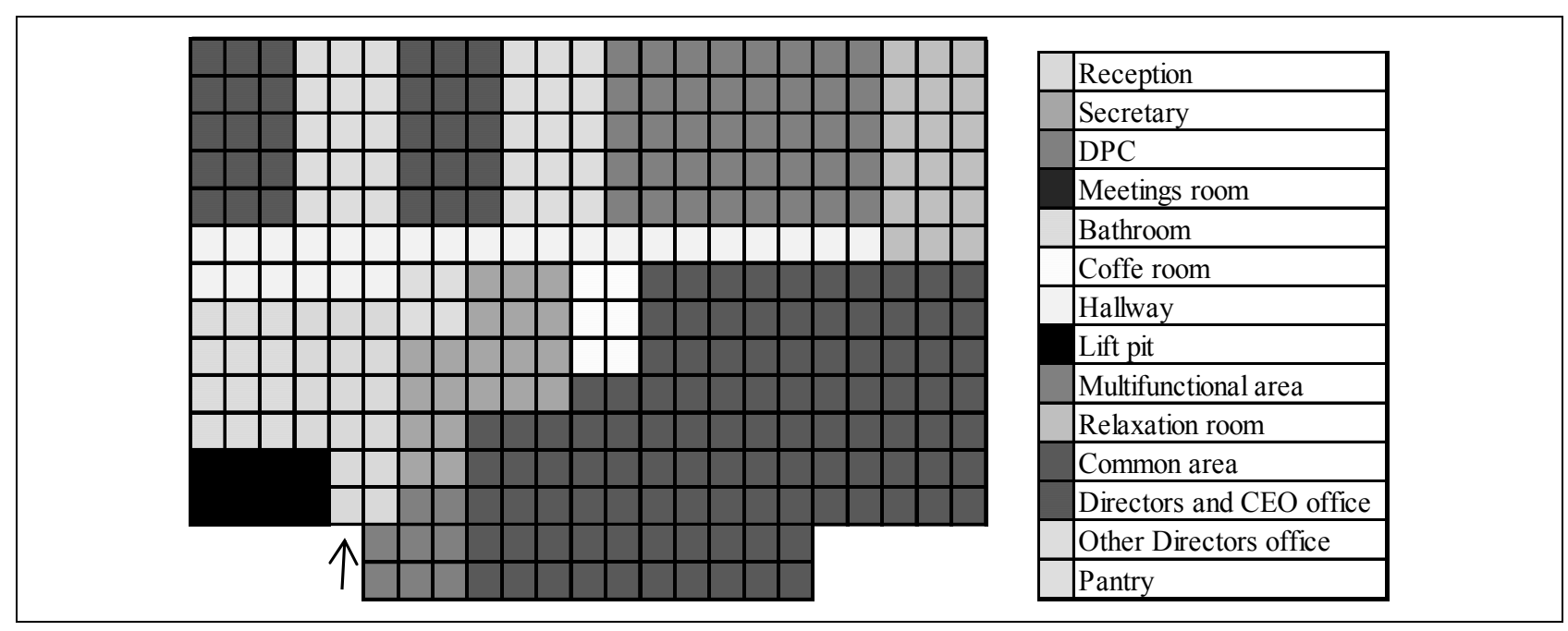

Figure 7. Layout alternative 2.

The administration office in this layout is closer to the directors' and CEO's office, which are more distant from the common social area. The room for individual work is also close to the window. The $4 \mathrm{~m}^{2}$ area above the data processing center is occupied by the company file. 
Winner alternative. The winner alternative choice was made mainly considering the importance of a multi-purpose room and a common social area, proximity to windows, the company's capacity expansion, and the impact on customers. In both alternatives, the enterprise would have a multi-space configuration, with spaces to individual or group activities, supporting all the stages of the organizational creative process (Moultrie et al., 2007; Haner, 2005; Boutellier et al., 2008).

In alternative 1 , it is possible to notice that all the top management rooms have windows as well as the multifunctional room. However, in alternative 1, the common social area has no windows. Another problem is that the company, in this alternative, would be working at full capacity, with no possibility of expansion. In the case of a client visit, the client would walk a short distance through the company, being straightly led to the meeting room.

In alternative 2, the top management offices, the common social area, and the multifunctional room have windows. The common social area would receive natural light just as in alternative 1 . The advantage is that in this alternative, there is a great expansion opportunity, if the meeting room is removed. This is possible because the multi-purpose room can be also used as a meeting room. The customer would have to walk through the company to reach this room; in this way, the client would visit the whole company. This can be positive, once the customer would be in contact with the company's style and meet the staff, which stimulates the creation of bonds.

Also, a bigger common social area and multi-purpose room is an important advantage, as they are strategical for informal knowledge sharing and in the creative process, in the stages which demand group interaction. Bigger environments offer more options to put into practice the layout suggestions made by several authors.

Analyzing these factors, alternative 2 was chosen as the winner. Besides the fact that in this alternative, the top management's offices are together, which facilitates the communication, it aggregates several concepts that have been previously presented. The elimination of the meeting room can be compensated by the existence of the multi-purpose room, which can become two different environments and in consequence two meeting rooms.

Detailed layout. The multi-purpose room will now be explained in further detail. This area is designed to become more than one space. It must possess the minimum requirements for a room which may hold meetings and receptions and must be easily rearranged. Creativity is enhanced with the break of monotony and this can be achieved by the necessity of changing this room configuration depending on the purpose.

This room should have casual atmosphere, adjustable furniture, and devices for information retention and presentation abilities, for example, brainstorming systems and movable whiteboards (Augustin \& Brand, 2001).

Firstly, all the furniture must have wheels and there should be a long modular table, so that it can be turned into two or three tables. There should be also a great availability of information, such as a bookcase-also movable - with newspapers, books, and magazines. Internet and retroprojector access would be done by notebook.

Secondly, there must be a movable wall which can separate the room into two. This wall must have good sound insulation, such as the "box of eggs" type and at the same time be light. With these facilities, the room can really become multifunctional, acting, for example, as meeting room on one side and study room on the other one.

It is important that this room has elements to stimulate the externalization and socialization of information: a big white board, Wi-Fi network, projector, and video conferencing. 


\section{Conclusions}

A study was conducted to evaluate an enterprise's work environment, considering that the work conducted by the employees is necessarily cognitive and creative. The objective was to propose changes which could turn the environment more favorable for the activities led by the workers.

Based on the literature review, different alternatives for the layout were proposed, in order to be adequate to different stages in the production process, each one having different requirements. Among these different environments, it is possible to highlight a room for individual work, an open office, a common social area, and a multi-purpose room.

The multi-purpose room's layout was discussed in further detail; the objective of this environment is to be a space which stimulates knowledge externalization and socialization and at the same time be also projected to stimulate the creativity with elements to break the monotonicity.

Future research will further the development of a model for planning the facilities of knowledge based companies through the lens of engineering. Future works may also be inspired to combine industrial engineering tools to psychology knowledge in order to expand and adapt the decades old industrial studies to creative services providers and research and development departments.

\section{References}

Augustin, S., \& Brand, J. (2001). Impact of the physical environment on knowledge worker performance (EDRA 32: Workplace performance and productivity session, Edinburgh, Scotland).

Block, L., \& Stokes, G. (1989). Performance and satisfaction in private versus non-private work settings. Environment and Behavior, 21(3), 277-297.

Boutellier, R., Ullman, F., Schreiber, J., \& Naef, R. (2008). Impact of office layout on communication in a science-driven business. R\&D Management, 38(4), 372-391.

Brennan, A., Chugh, J. S., \& Kline, T. (2002). Traditional versus open office design: A longitudinal field study. Environment and Behaviour, 34(3), 279-299.

Brooks, A. (1998). Ergonomic approaches to office layout and space planning. Facilities, 16(3-4), 73-78.

Chien, T. K. (2004). An empirical study of facility layout using a modified SLP procedure. Journal of Manufacturing Technology Management, 15(6), 455-465.

Danielsson, C., \& Bodin, L. (2008). Office type in relation to health, well-being, and job satisfaction among employees. Environment and Behavior, 40(5), 636-668.

De Carlo, F., Arleo, M. A., Borgia, O., \& Tucci, M. (2013). Layout design for a low capacity manufacturing line: A case study. International Journal of Engineering Business Management. Special Issue on Innovations in Fashion Industry, 5(35), 1-10.

Doorley, S., \& Witthoft, S. (2012). Make space: How to set the stage for creative collaboration. Hobo-ken, NJ: John Wiley \& Sons Inc.

Haner, U. E. (2005). Spaces for creativity and innovation in two established organizations. Creativity and Innovation Management, $14(3), 288-298$.

Heragu, S. S. (2006). Facilities design (2nd ed.). Lincoln, NE: iUniverse.

Hong, J. C., Hwang, M. Y., \& Lin, C. L. (2003). Chi and organizational creativity: A case study of three Taiwanese computer firms. Creativity and Innovation Management, 12(4), 202-210.

Iida, I. (2005). Ergonomia: Projeto e produção (2nd ed.). São Paulo, SP: Edgard Blücher.

Kristensen, T. (2004). The physical context of creativity. Creativity and Innovation Management, 13(2), 89-96.

Magadley, W., \& Birdi, K. (2009). Innovation labs: An examination into the use of physical spaces to enhance organizational creativity. Creativity and Innovation Management, 18(4), 315-325.

Meyers-Levy, J., \& Zhu, R. (2007). The influence of ceiling height: The effect of priming on the type of processing that people use. Journal of Consumer Research, 34(2), 174-186.

Moultrie, J., Nilsson, M., Dissel, M., Haner, U. E., Janssen, S., \& Der Lugt, R. V. (2007). Innovation spaces: Towards a framework for understanding the role of the physical environment in innovation. Creativity and Innovation Management, 
$16(1), 53-65$.

Muther, R. (1973). Systematic layout planning (2nd ed.). Ann Arbor, MI: Cahners Books.

Ojaghi, Y., Khademi, A., Yusof, N. M., Renani, N. G., \& Hassan, S. A. H. S. (2015). Production layout optimization for small and medium scale food industry. Procedia CIRP, 26, 247-251.

Oksanen, K., \& Ståhle, P. (2013). Physical environment as a source for innovation: Investigating the attributes of innovative space. Journal of Knowledge Management, 17(6), 815-827.

Peschl, M., \& Fundneider, T. (2014). Designing and enabling spaces for collaborative knowledge creation and innovation: From managing to enabling innovation as socio-epistemological technology. Computers in Human Behavior, 37, 346-359.

Shayan, E., \& Chittilappilly, A. (2004). Genetic algorithm for facilities layout problems based on slicing tree structure. International Journal of Production Research, 42(19), 4055-4067.

Shibata, S., \& Suzuki, N. (2002). Effects of the foliage plant on task performance and mood. Journal of Environmental Psychology, 22, 265-272.

Shibata, S., \& Suzuki, N. (2004). Effects of an in-door plant on creative task performance and mood. Scandinavian Journal of Psychology, 45, 373-381.

Steidle, A., \& Werth, L. (2013). Freedom from constraints: Darkness and dim illumination promote creativity. Journal of Environmental Psychology, 35, 67-80.

Stokols, D., Clitheroe, C., \& Zmuidzinas, M. (2002). Qualities of work environments that promote perceived support for creativity. Creativity Research Journal, 14(2), 137-147.

Stone, N. J., \& Irvine, J. M. (1994). Direct and indirect window access, task type, and performance. Journal of Environmental Psychology, 14, 57-63.

Tompkins, J. A., White, J. A., Bozer, Y. A., \& Tanchoco, J. M. A. (2010). Facilities planning (4th ed.). Hoboken, NJ: John Wiley and Sons, Inc.

Van Donk, D. P., \& Gaalman, G. (2004). Food safety and hygiene: Systematic layout planning of food processes. Chemical Engineering Research and Design, 82(11), 1485-1493.

Wallas, G. (1926). The art of thought. New York, NY: Harcourt Brace Jovanovich.

Wiyaratn, W., \& Watanapa, A. (2010). Improvement plant layout using systematic layout planning (SLP) for increased productivity. World Academy of Science, Engineering and Technology, 4(12), 309-313.

Yang, T., Su, C. T., \& Hsu, Y. R. (2000). Systematic layout planning: A study on semiconductor wafer fabrication facilities. International Journal of Operations \& Production Management, 20(11), 1359-1371.

Yin, R. K. (2014). Case study research: Design and methods (5th ed.). Thousand Oaks: SAGE Publications. 